\title{
EtNiZACión Y MULTiCUlturalismo
}

\author{
en el bajo Atrato
}

\author{
EDUARDO RESTREPO \\ Profesor asociado, Departamento de Estudios Culturales, \\ UNIVERSIDAD JAVERIANA, Bogotá \\ eduardoa.restrepo@gmail.com
}

\begin{abstract}
Resumen
[n este artículo busco examinar, para un lugar específico (el bajo Atrato, en el departa[mento del Chocó), algunos efectos del multiculturalismo. Para ello me enfoco en los alcances y límites del proceso de etnización de las “comunidades negras", resaltando los efectos performativos de la legislación inspirada en el giro al multiculturalismo que constituye, en la imaginación jurídica y política, a estas comunidades como un "grupo étnico". Me interesa más el examen de la emergencia del proceso de etnización que presentar un diagnóstico de la situación organizativa actual del bajo Atrato y de las intervenciones que entidades no gubernamentales (colombianas y extranjeras) o el Estado realizan hoy de acuerdo con el derecho internacional humanitario.

PALABRAS ClAVE: etnización, multiculturalismo, bajo Atrato, Chocó, comunidades negras, afrodescendientes.
\end{abstract}

\section{Ethinicization AND Multiculturalism \\ in Bajo Atrato}

\begin{abstract}
This article examines some of the effects of multiculturalism in a specific place: the lower Atrato River in the Colombian Department of Chocó. In order to do this I focus on the scope and reach of the process of ethnicization of 'black communities'. I highlight the performative effects that the legislation inspired by the multicultural turn-and which constituted 'black communities' as an ethnic group — has had on the Colombian juridical and political imagination. I am more interested in examining the emergence of an ethnicization process in the lower Atrato than in diagnosing the current organizational situation in the region, as well as of non-governmental interventions (both Colombian and foreign) or State initiatives which are taking place today in response to international humanitarian law or to the return of displaced populations.

KEY WORDS: ethnicization, multiculturalism, lower Atrato River, Chocó, black communities, afro-descendants.
\end{abstract}

Revista Colombiana de Antropología

Volumen 47 (2), julio-diciembre 20II, pp. 37-68 
Aún hay un largo trabajo etnográfico por hacer acerca del modo en que la

Ley 70 transforma la vida social, productiva, politica y cultural de las comunidades negras. Daniel Ruiz, "Nuevas formas de ser negro"

\section{INTRODUCCIÓN}

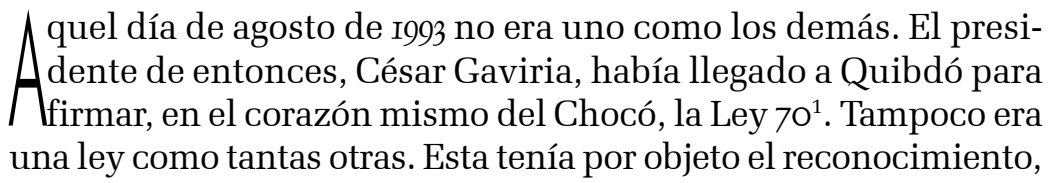
por parte del Estado colombiano,

I. Los referentes empíricos de este artículo son el resultado del apoyo al proceso de sistematización adelantado por la Asociación de Organizaciones y Consejos Comunitarios del Bajo Atrato (Ascoba) y por un equipo de trabajo, del cual hice parte, del Centro de Pensamiento de América Latina Raiz.AL. Agradezco a Nadia Umaña y Josué Sarmiento por la invitación a hacer parte del equipo. En esa labor contamos con el decidido apoyo de Daniel Ruiz Serna (quien trabajó durante varios años con el Cinep en la zona) y de Ernesto Ramírez (presidente de Ascoba). Quiero dar un agradecimiento muy especial a Armando Valencia, de la parroquia de Riosucio, por su generoso apoyo durante los viajes del equipo de Raiz.AL al bajo Atrato, así como por compartir sus conocimientos, historias y reflexiones sobre el proceso organizativo y la región. Igual deuda cabe con William Villa, colega como pocos en la fascinación compartida por el Pacífico. Agradezco, igualmente, los detallados comentarios y críticas realizadas al primer borrador de este texto por Julio Arias y un lector anónimo asignado por la revista. No sobra resaltar que estos agradecimientos no buscan endosarles a amigos y colegas lo que no es más que responsabilidad propia por las erráticas interpretaciones que puedan ser halladas en este artículo. de las "comunidades negras" como "grupo étnico". Desde la perspectiva de diversos actores, dicha ley era el logro jurídico más importante en los últimos I5O años para los descendientes de los africanos en Colombia. Después de la ley de abolición de la esclavitud, por allá en I85I, durante el gobierno liberal de José Hilario López, con la ley que ese día se estaba firmando las “comunidades negras" del país eran reconocidas por vez primera en términos jurídicos como un "grupo étnico", con unos derechos territoriales específicos y una cultura e identidad propias.

Para quienes entendían así la ley, ese era un pequeño pero importante paso en la lucha contra la discriminación y la invisibilidad que han imperado desde siempre y que han borrado de un plumazo los aportes y la presencia de los africanos y sus descendientes en la historia del país. Además, esta ley tenía la particularidad de que organizaciones negras de todo el Pacífico colombiano, y de algunas otras regiones, habían participado directa y activamente en la redacción del texto, y habían discutido durante meses con funcionarios del Gobierno y otros expertos sus términos y alcances. Capítulo tras capítulo, 
la propuesta de ley que ahí se firmaba había nacido de una intensa y difícil negociación en el marco de la Comisión Especial para las Comunidades Negras, creada en 1992. No era todo lo que los representantes de las organizaciones habían pretendido incluir, pero sin lugar a dudas el texto recogía muchas de sus aspiraciones.

En todo caso, para los representantes de las organizaciones estaba claro que la ley no había sido ningún regalo del Gobierno, sino que era el resultado del arduo trabajo de ellos y de sus comunidades, que habían logrado abrir un espacio. La versión final de la ley que la Comisión Especial presentó al Congreso había sido objeto del más intenso debate y, no en pocas ocasiones, de manifiestas posiciones encontradas. Quedaron por fuera muchas propuestas y puntos que las organizaciones querían introducir y consideraban fundamentales. Ahora bien, desde la perspectiva del Gobierno que la firmaba, esa ley constituía un desarrollo de la por aquel entonces reciente Constitución Política. Así lo hizo saber el presidente en el discurso que pronunció en Quibdó. A sus ojos, la ley representaba un acto concreto de avance en la materialización del principio constitucional del derecho a la diferencia cultural.

Nacida de un artículo transitorio decretado al final de la Asamblea Nacional Constituyente, la Ley 70 de 1993 constituye uno de los más evidentes mojones de la inscripción de las comunidades negras en la lógica del multiculturalismo impulsada por el Estado colombiano desde los años noventa (Pardo 200I, Rojas 2004). Desde entonces, la Corte Constitucional ha producido una serie de sentencias que han ampliado, al menos jurídicamente, los términos en los cuales el Estado constituye e interpela a un sujeto de derecho ahora referido como población afrodescendiente (Mosquera y León 2009).

En este artículo busco examinar algunos efectos del multiculturalismo para un lugar específico, el bajo Atrato, en el departamento del Chocó. Mi argumento es que los cuestionamientos antropológicos al multiculturalismo requieren una aproximación etnográfica que identifique, de forma situada, las transformaciones que se han sucedido a propósito de su concreción y despliegue, sin perder de vista las variaciones y tensiones entre diferentes sectores e individuos. Esto no significa, sin embargo, que la valoración de la diferencia no tenga que ser defendida, ni que se desconozcan los aportes del multiculturalismo a esta valoración. 
El artículo comienza con una serie de precisiones analíticas referentes a las categorías de etnización y multiculturalismo. Luego examino las dinámicas poblacionales en el bajo Atrato y la historia del proceso organizativo, que confluyen en la etnización en el marco del multiculturalismo. Finalmente, me ocupo de las problemáticas que se derivan de esta etnización, centrándome en las tensiones entre poblaciones locales y en sus improntas raciales y culturalistas.

\section{Precisiones analíticas}

nte todo, con etnización quiero indicar la idea de proceso, y, en tanto proceso, se pueden rastrear unos momentos en los cuales emerge, así como una serie de despliegues y dispersiones. No considero, sin embargo, que sea un proceso homogéneo ni que suponga que todo lo que existía antes haya desaparecido como por arte de magia, de la noche a la mañana. No todos los individuos o ámbitos son interpelados de la misma manera, con análogos efectos e idéntica densidad.

La especificidad del proceso que llamo etnización radica en la formación de un sujeto político en un sentido amplio (un nosotros/ellos), y de unas subjetividades (unas identificaciones), en nombre de la existencia (supuesta o efectiva) de un "grupo étnico". Por tanto, entiendo por etnización el proceso en el cual unas poblaciones son constituidas y se constituyen como "grupo étnico". He enfatizado esta expresión porque no me interesa definir en abstracto qué es (o no) un grupo étnico. Me interesa, en cambio, examinar etnográfica e históricamente cómo es entendido y con qué efectos, en momentos, lugares y entramados institucionales concretos, por personas específicas, eso de grupo étnico. $\mathrm{O}$, en otras palabras, cómo se imagina y disputa el mundo apelando (o no) a ciertas nociones (siempre multiacentuales y contradictorias) de grupo étnico. En consecuencia, no busco proponer unos criterios analíticos que equiparen o diferencien esta categoría, de una vez por todas y con solar claridad, de otras que suelen estar bien cercanas, como las de raza, cultura y nación.

Con la idea de etnización me interesa, por tanto, examinar el proceso mediante el cual se ha disputado lo que en un momento y contexto concretos aparece como grupo étnico, los criterios 
utilizados, los discursos de expertos y las políticas de la verdad que esta categoría involucra, y, sobre todo, las prácticas que se derivan para determinados sujetos (que parcialmente son constituidos como tales por la etnización que los interpela y refiere). $\mathrm{Mi}$ argumento es que las yuxtaposiciones o distinciones de grupo étnico con otras categorías, los contenidos asignados y sus múltiples apropiaciones requieren ser examinadas etnográfica e históricamente.

En Colombia, la noción de grupo étnico ha operado históricamente en un doble campo semántico, que es importante observar analíticamente para comprender las implicaciones del concepto de etnización que aquí propongo. En primer lugar, al menos desde principios del siglo $\mathrm{xx}$, se puede rastrear entre ciertos intelectuales una utilización del término de grupo étnico para referirse a "blancos", "negros" e "indios", como sinónimo o en sustitución de raza (cfr. López I920a, I920b, I934). Así, se habla de los tres grupos étnicos (o razas) que conformaron la nación colombiana. Al mestizo, que sería el producto de las diferentes mezclas, se lo ha considerado también como un grupo étnico, al igual que a sus diferentes expresiones regionales. De esta manera, por ejemplo, Manuel Zapata Olivella (I974) concibe como grupos étnicos actuales los siguientes: el antioqueño, el cundiboyacense, el tolimo-huilense, el santandereano, el costeño, el caucano, el llanero u oriental y el subgrupo isleño. Este campo semántico, como sinónimo o como sustitución de raza o población, se caracteriza porque la noción de grupo étnico es aplicable a unidades geopoblacionales o a categorías sociales diversas, que compondrían en su totalidad la idea de pueblo, cultura o nación colombiana. Los colombianos todos, cualesquiera sean las unidades de diferenciación y taxonomías utilizadas, hacen parte de grupos étnicos.

El segundo campo semántico en el que ha operado la noción de grupo étnico se caracteriza por restringirla a "comunidades" tradicionales, culturalmente diferentes y territorializadas, que se imaginan como otros de Occidente y de la modernidad. En el discurso jurídico, así como en el académico y el político, ha predominado en las últimas décadas la idea de que los indígenas son el paradigma de la noción de grupo étnico. La existencia de marcadores de la diferencia, como los lingüísticos y los culturales, expresados en ciertas formas de vida comunitarias, tradicionales y territorializadas, es el criterio que se esgrime frecuentemente 
para concebir a una población determinada como grupo étnico. En este sentido, no todos los colombianos son miembros de tales grupos, sino solo algunos: los indígenas inicialmente, las "comunidades negras" después y, más recientemente, los raizales y el pueblo rom. Esta es la concepción de grupo étnico que se ha hecho "sentido común" en las últimas dos décadas en el país.

Ahora bien, en este campo semántico, no es suficiente la diferencia cultural para que se hable de grupo étnico. Se suele considerar que los habitantes de la costa colombiana, por ejemplo, tienen diferencias lingüísticas, culturales y fenotípicas claras con los de otras áreas del país. Pero antes que suponer a estos habitantes como un grupo étnico, se los piensa en términos de diferencia regional. Otro ejemplo es el de los paisas. Con este término se conoce en gran parte del país a los individuos provenientes de una región que se corresponde más o menos con

2. En el Pacífico colombiano, sin embargo, paisa tiene otra connotación: la de "blanco" proveniente del interior del país. Un bogotano, un tolimense y un antioqueño "blancos" son catalogados igualmente como paisas. los departamentos de Antioquia, Caldas y Risaralda². Los paisas son fácilmente identificables por su particular manera de hablar y sus singularidades culturales, pero sobre todo por un profundo sentido de pertenencia y una actitud de hipervaloración de lo propio. No obstante, en este campo semántico, no se suele considerar esta diferencia en términos de grupo étnico, sino que se la encuadra en el discurso de la diferencia regional.

Hoy, en Colombia, no hay una equivalencia entre grupos étnicos y comunidades indígenas, aunque cierta concepción de indianidad es la garantía y el referente último para llegar a ser considerado como grupo étnico. Las "comunidades negras" han logrado este tipo de reconocimiento. En las últimas décadas, en la legislación y en los imaginarios políticos y académicos la negridad ha sido articulada como grupo étnico. Para hacerlo, se ha requerido de un proceso de marcación y otrerización comunitarista y etnicista que se remonta a mediados de los años ochenta (cfr. Agudelo 2005; Castillo 2007).

Etnización es el concepto propuesto para dar cuenta de este proceso, que no es monolítico ni ha sido igualmente apropiado y significado en todos los niveles, ni por todos los actores y las poblaciones en nombre de las cuales se habla. Por etnización no se entiende únicamente el proceso que involucra las acciones o 
planes explícitos de las diferentes entidades estatales y organizaciones no gubernamentales para las "comunidades negras" (o, más tarde, aunque algo imprecisamente, los afrodescendientes) en tanto grupo étnico. La etnización tampoco se agota en lo que las organizaciones étnico-territoriales y sus activistas hacen o enuncian en cuanto tales, ni en lo que los académicos elaboran sobre las "comunidades negras" como grupo étnico. Las apropiaciones locales, con sus diversas interpretaciones, interpelaciones y rechazos, hacen parte también de la etnización de la negridad. Así pues, la etnización implica una serie de disputas entre los diferentes actores que son parcialmente constituidos y sus posiciones, definidas en tal proceso. Estas disputas buscan intervenir en las relaciones de poder existentes, apelando a la especificidad de una población o poblaciones definidas en este proceso con base en una comunalidad étnica. Antes que una articulación consensuada y homogénea, la idea de las "comunidades negras" como grupo étnico ha sido el objeto de múltiples disputas.

Este continuo y conflictivo proceso incluye la configuración de un campo discursivo y de visibilidades desde el cual se constituye el sujeto de la etnicidad. Igualmente, demanda una serie de mediaciones que hacen posible no solamente el campo discursivo y de visibilidades, sino también las modalidades organizativas que se instauran en nombre de la comunidad étnica. Por último, pero no menos relevante, este proceso se asocia a la formación de conjunto de las subjetividades correspondientes.

Por lo argumentado, la noción de etnización no supone una etnicidad que estaría dada de antemano, como una suerte de esencia de las poblaciones que esperaría a ser exorcizada por el auge del movimiento organizativo, por las condiciones favorables desplegadas por la reciente legislación o por la labor de asesores y funcionarios. Al contrario, con la idea de etnización se busca indicar una sutil filigrana de mediaciones y tecnologías que han hecho pensable (han, literalmente, producido) a las "comunidades negras" como grupo étnico, lo cual ha posibilitado no solo la legitimidad de organizaciones de carácter étnico-territorial, sino también de las intervenciones del Estado y otros actores a nombre de dichas "comunidades". Este artículo tiene entre sus propósitos, precisamente, contribuir con unos aportes desde la etnografía y, situadamente, a la comprensión de la etnización de la negridad. 
El término multiculturalismo no está tampoco exento de ambigüedades. Siguiendo a Stuart Hall (2000/2010), me ha parecido relevante, en términos analíticos, distinguir entre multiculturalismo y multiculturalidad. Esta última hace referencia al hecho de que cualquier formación social es culturalmente heterogénea. No hay sociedad, por pequeña y aislada que parezca, donde no se puedan encontrar diferencias culturales generacionales, de género, de proveniencia o de trayectorias (Grimson 20II). Y esto es evidente en el grueso de las formaciones sociales, en las que confluyen las más disímiles poblaciones en los más variados lugares; o en un mundo donde los flujos de imágenes, objetos y prácticas circulan en ciertas direcciones. Desde esta perspectiva, la multiculturalidad es un hecho social: la heterogeneidad cultural que existe por doquier, con mayor o menor fuerza, pero siempre presente.

Por multiculturalismo, en cambio, entiendo las políticas adoptadas en una formación social determinada con respecto a esta heterogeneidad cultural. Así, por ejemplo, el multiculturalismo implicaría las medidas jurídicas que en el marco de un Estado-nación se adoptan en aras de reconocer la diversidad cultural. Pero, más allá de estas medidas, el multiculturalismo así entendido involucra una serie de supuestos y conceptualizaciones que, como una matriz epistémica asumida, producen lo que aparece como diferencia cultural (y por lo tanto lo que no es registrado como tal) y el mapa de su importancia y de su valoración. El multiculturalismo no solamente visibiliza las diferencias preexistentes, sino que las produce de dos maneras, principalmente: I) al hacer énfasis sobre rasgos o aspectos de alguna manera existentes pero que hasta entonces no habían sido considerados como marcadores de diferencia; y 2) al apuntalar la emergencia de marcadores de diferencia que no tienen sustento en las prácticas de las poblaciones que son interpeladas, y que constituyen, más bien, esfuerzos por configurar comunalidades idealizadas.

Si el multiculturalismo se entiende como estas políticas referidas a la heterogeneidad cultural (esto es, con respecto a la multiculturalidad), y los supuestos y conceptualizaciones subyacentes, entonces no habría un solo multiculturalismo, sino diferentes (y en algunos casos, contradictorios). Siguiendo en esto todavía a Hall (2000/2010, 584), analíticamente se puede diferenciar entre multiculturalismos conservadores, neoliberales, radicales y comunitaristas, entre otros. Lo relevante de este 
planteamiento es que no se puede establecer una necesaria correspondencia entre el multiculturalismo y una ideología política determinada. O, para plantearlo de otra manera, el hecho de que en muchos países de América Latina, durante los años noventa, se haya dado lo que Evelina Dagnino (2004) ha denominado una perversa confluencia en las transformaciones constitucionales, entre la implementación del neoliberalismo y el posicionamiento del multiculturalismo, no significa que existe una relación inmanente e indisoluble entre los dos $^{3}$.

Otra distinción puede realizarse entre una conceptualización del multiculturalismo de corte minimalista y una maximalista. La primera argumenta que el multiculturalismo es una política de Estado y que se materializa en las medidas tomadas en torno a la diversidad cultural. La legislación, pero también los programas e iniciativas implementadas por las diversas entidades y agencias estatales, constituirían una serie de políticas en un momento determinado, y establecerían los particulares contornos del multiculturalismo para un Estado. En contraste, una conceptualización maximalista retoma los planteamientos de Foucault (I978/1999) sobre la gubernamentalidad para argumentar que el multiculturalismo no se circunscribe a las

3. Sobre esta confluencia, se pueden consultar los trabajos de Gros (1999), Hale (2002), Pardo (2002) y Wade (1996).

4. Se ha hecho un lugar común cuestionar la apelación a la noción de gubernamentalidad foucaultiana en nombre de los agenciamientos de sectores subalternizados, o de la irreductible heterogeneidad y desbordamientos constitutivos de la vida social. Mi posición, que obviamente no puedo argumentar en detalle en este artículo, es que gubernamentalidad no implica necesariamente un vaciamiento de tales agenciamientos o una borradura de tales heterogeneidades o desbordamientos. Con muchas de estas críticas se tiene la sensación de que tienden a reeditar la vieja discusión entre estructura/agencia y a atribuirle erráticamente a la gubernamentalidad el lugar de simple estructura.

políticas del Estado, sino que supone un arte de gobierno que constituye unas particulares poblaciones en nombre de cuyo bienestar se regula su vida social ${ }^{4}$.

Como lo ha sugerido Inda (2005), la categoría de gubernamentalidad foucaultiana, en lo metodológico, implica tres planos estrechamente relacionados: I) las racionalidades involucradas, esto es, la multiplicidad de enunciados de los saberes expertos que, con determinados efectos de verdad, posibilitan la producción de objetos, posiciones de sujeto, conceptos y tácticas desde los cuales hace sentido el despliegue de una serie de regulaciones de las poblaciones así constituidas; 2) las tecnologías desplegadas, esto es, las formas de hacer que se articulan como intento de respuesta a las problemáticas constituidas por aquellas 
racionalidades; y 3) las subjetividades que son interpeladas en el juego de las racionalidades y tecnologías indicadas. No sobra precisar que me identifico más con una conceptualización del multiculturalismo como gubernamentalidad que con la que lo circunscribe a unas políticas de Estado.

Dado que el multiculturalismo puede ser considerado como aquella política de Estado o gubernamentalidad articulada en nombre de la diversidad cultural en general, considero que analíticamente es pertinente referirse al multiculturalismo etnicista como aquel que opera dentro de una particular apelación de la diversidad cultural: la del otro-étnico de la nación. Los otros de la nación, como bien lo explican Claudia Briones (2002) y Rita Laura Segato (2007), implican y operan dentro de formaciones nacionales de alteridad con densidades históricas y variaciones significativas de un país a otro. En Colombia, el otro-étnico de la nación perfilado por el multiculturalismo etnicista ha tenido como paradigma cierto imaginario de una indianidad marcada como tradicionalidad, autenticidad y comunalidad, ubicada en ciertas geografías (lo rural, el resguardo, las selvas, la Sierra Nevada de Santa Marta, el macizo colombiano...) y temporalidades (no modernas, no occidentales), y ha perfilado un particular sujeto moral (el nativo ecológico) ${ }^{5}$. Este paradigma ha operado como una especie de normativización acerca de quiénes pueden ser interpelados o no como sujetos del multiculturalis-

5. Este concepto ha sido argumentado por Astrid Ulloa (2004).

6. Aquí me inspiro en la argumentación de Alcida Ramos (I998) sobre el indígena hiperreal. mo etnicista. Pese a que muchos de quienes han sido reconocidos como otros-étnicos de la nación no encarnan dicho paradigma, no por ello este ha dejado de operar como una especie de sujeto étnico hiperreal ${ }^{6}$. La fuerza de este paradigma se hizo sentir en las discusiones de expertos, representantes y políticos acerca de si los negros eran o no un grupo étnico, que fueron decisivas en el trabajo de la Comisión Especial para Comunidades Negras y el texto de la Ley 70. 


\section{CONFIGURACIÓN POBLACIONAL}

$\left\{\begin{array}{l}\text { diferencia de otros lugares del Pacífico colombiano, en el } \\ \text { bajo Atrato los negros }{ }^{7} \text { se han encontrado estrechamente re- } \\ \text { lacionados desde hace varias generaciones con varios grupos }\end{array}\right.$ poblacionales. La heterogeneidad de la estructura poblacional del bajo Atrato es el resultado de particulares procesos históricos que se remontan al periodo colonial. Al lado de los negros, en zonas rurales y urbanas se encuentran chilapos, paisas, costeños y cholos. El grueso de las poblaciones indígenas, conocidas localmente como cholos $^{8}$, no son las que habitaban estos lugares durante la Colonia (Vargas I999). Los emberas han migrado durante el siglo xx del medio y alto Atrato, así como del Baudó, dado el repliegue y debilitamiento de los tules (denominados por los españoles como cunas o cunacunas), que eran los dueños y señores de estos parajes ${ }^{9}$. Así, por ejemplo, en un estudio sobre la cuenca del río Cacarica, Carlos Andrés Meza indica cómo algunos de los pobladores negros pioneros que llegaron del Baudó propiciaron la llegada de algunos emberas: "Del Baudó también llegaron sus compadres emberas, gracias a los aventureros afros

7. De aquí en adelante, se resaltan con cursivas las palabras con significados locales.

8. El término cholo tiene connotaciones despectivas, pues se encuentra asociado a la desnudez, al monte, a la animalidad y a lo tosco. Es lo opuesto a los cuerpos, hábitos y espacios "civilizados".

9. Los tules, que ahora habitan en Panamá, ofrecieron una exitosa resistencia a las pretensiones de dominación españolas. Se aliaron con ingleses, franceses y holandeses para hacer del bajo Atrato un lugar vedado y temido hasta tal punto que, bajo pena de muerte, fue prohibida por la Corona la navegación por este río por cerca de un siglo (Colombia, Contraloría General de la Nación I943, 3I).

IO. Rastrear estos movimientos poblacionales de los indígenas en las diferentes cuencas del bajo Atrato es muy importante para entender las complejidades de los procesos de poblamiento y para problematizar el imaginario de que los indígenas siempre han estado alli, de que sus presencias son necesariamente y en todas partes anteriores y originarias. que les convidaron a migrar [...]" $(2006,396)^{10}$.

El poblamiento negro del bajo Atrato se produjo, principalmente, desde mediados del siglo xIx, como parte de los flujos poblacionales provenientes del curso medio y alto del río Atrato, y de los ríos San Juan y Baudó (Osorio 2006, 77; West 1957). Al respecto, el sociolingüista español Germán de Granda escribía:

[...] las migraciones por parte de los antiguos esclavos negros y sus familias, liberados por la Ley de la República en I85I, desde la zonas dedicadas a la explotación aurífera a otras en que, abandonando su antigua y forzada profesión minera, podrían dedicarse a la 
agricultura o la pesca. Una rama de esta corriente migratoria, formada por exesclavos originarios del Alto Atrato y de la comarca del San Juan, parece haber descendido la corriente del Atrato fundando, a su paso, varios caseríos como Napipí, La Isla de los Palacios, El Montaño (que aún recuerdan la procedencia sanjuanera de parte de sus familias) y, finalmente, en la zona llamada Playablanca, el que se llamó Riosucio. (I977, 20I)

Para la cuenca del río Cacarica, la tradición oral ha mantenido la referencia de que los primeros fundadores provenían del Baudó: "Según la historia local, el viejo [Higinio] Palacios salió del Baudó a explorar tierras sin hombres y se encontró en el Darién. Regresó, se llevó a su familia y les avisó a sus compadres indígenas del hallazgo. De ahí surgen asentamientos focales en la cuenca como San Higinio, en honor al antepasado fundador" (Meza 2006, 396).

Esta corriente migratoria se debe entender en el marco de las relaciones que el bajo Atrato ha sostenido con la costa atlántica, sobre todo con Cartagena, que fueron particularmente intensas durante el siglo xIx y la primera mitad del xx. Ciertamente, el bajo Atrato ha tenido históricamente una estrecha conexión con la costa atlántica, primeramente con Cartagena y luego con Barranquilla. Como anota Granda, ya en el siglo xix desde Cartagena "[...] pequeñas embarcaciones de vela o de motor central han mantenido un tráfico comercial relativamente importante con localidades [...] ubicadas en las orillas del Atrato, hasta Quibdó" (I977, 54). La migración de los libertos negros y sus familias, y la proveniente de Cartagena y sus alrededores, fueron incentivadas por las nacientes actividades extractivas asociadas al caucho, la tagua y la raicilla (ipecuana), que se recolectaban en la región para ser exportadas desde Turbo o Cartagena (Villa 2OII).

Granda afirma que hacia la segunda mitad del siglo xIx, paralela a la migración de los negros libertos y sus familias, en Riosucio confluyó otra corriente migratoria "[...] constituida por gentes, criollas o mulatas, desplazadas desde Cartagena y su comarca en busca de terrenos libres para dedicarse en ellos a la agricultura”. De esta manera, "[...] los vecinos más conocidos de la localidad [de Riosucio] eran todos cartageneros o de las cercanías de Cartagena, como José Prestán, Joaquín Vergara, Trinidad Garrido, Mariano Marrugo (de Turbaco), Fermín Ávila y Fermín Martínez" (1977, 202). 
Para mediados del siglo xx, el mismo autor identifica otra importante corriente migratoria, asociada a los chilapos: “[...] desde 1950 aproximadamente [...] desplazados de sus lugares de origen por las consecuencias antisociales del régimen de latifundios en ellos imperante [en los departamentos de Córdoba y Sucre], emigran hacia el oeste en busca de tierras de cultivo. Parece que los chilapos constituyen, en el Riosucio actual, un grupo no demasiado numeroso [...]" (Granda 1977, 202) ${ }^{11}$. Desde los años setenta se ha incrementado notablemente la presencia de los chilapos, que constituyen hoy en día, después de las poblaciones negras, el segundo grupo poblacional más numeroso en las zonas rurales del bajo Atrato (Ruiz 2006, 218).

En el bajo Atrato confluye también una corriente migratoria de paisas, que empezaron a tener mayor presencia en la región desde la apertura de la llamada

II. Al igual que cholo, la palabra chilapo tiene connotaciones negativas, ya que refiere a lo burdo, a lo rural, a lo basto. Por lo tanto, las personas provenientes de las sabanas de Córdoba y Sucre, a las que se denomina con este apelativo, suelen considerarlo como una especie de insulto.

I2. Más adelante se tratará el tema de la explotación comercial de la madera en el bajo Atrato y del papel desempeñado por Turbo como puerto de exportación. Sobre la historia de la construcción de la carretera al Mar y la instalación de la industria bananera en el Urabá antioqueño, ver Osorio (2006), Parson (I997) y Uribe (I992).

I3. Para citar un ejemplo, en el archivo de la parroquia de Riosucio se encuentran informes de los recorridos realizados, a finales de los años setenta y durante la primera mitad de los ochenta, por los misioneros y sus colaboradores a lo largo de diferentes ríos y zonas aledañas. Con respecto al río Truandó, afluente del margen occidental del Atrato, se puede leer en uno de estos informes: “La población de Truandó Medio está constituida principalmente por la raza negra. Se encuentran algunos colonos de Córdoba y paisas. Tiene la comunidad I5o habitantes aproximadamente. El caserío está conformado por io casas, las demás se encuentran dispersas. En las casas viven hasta 8 o Io personas".

I4. Así, por ejemplo, en la cuenca del Cacarica "[e] xistían comunidades como Bijao-Cacarica, Bendito Bocachico, Puente América, La Virginia, carretera al Mar, que después de una larga construcción conectó a Medellín con Turbo en 1954 (Villa 20II, Wade 1997). Esta carretera se asocia a la relevancia que unas décadas antes empezaran a adquirir Turbo y el Urabá antioqueño debido al cultivo comercial del banano y a la exportación de madera en bruto ${ }^{12}$.

El resultado de estos múltiples procesos de poblamiento del bajo Atrato es un panorama de confluencia, en distintos momentos, de diversas gentes que se han articulado e influenciado mutuamente, sin por ello perder sus especificidades históricas, sus racionalidades económicas y ambientales y sus configuraciones culturales ${ }^{13}$. En las zonas rurales del bajo Atrato se mantiene la tendencia de que los indígenas se establezcan en unas áreas, mientras que los negros y chilapos lo hagan en otras ${ }^{14}$. Los paisas, por su parte, aunque se encuentran como colonos con sus 
Villa Hermosa, San Higinio y Bocachica, donde la mayoría era afrodescendiente; y otras como Santa Lucía, Quebrada Bonita, Balsagira, San José de la Balsa, Quebrada del Medio y Bogotá, con un fuerte componente de chilapos y paisas" (Meza 2006, 396). familias en la zona rural, tienden a encontrarse más fácilmente en los cascos urbanos, dedicados a actividades comerciales (Ruiz 2006, 219).

\section{DE LAS LUCHAS CAMPESINAS A LO ÉTNICO- TERRITORIAL}

[l proceso organizativo en el bajo Atrato se remonta a los años

- setenta, cuando empiezan a constituirse las primeras juntas de acción comunal con el propósito de mejorar las condiciones de vida de los habitantes de las zonas rurales y de algunos poblados (Ramírez s. f., 4; Valencia 20II, 8-II). Las juntas de acción comunal se asociaron al inicial proceso de nucleación que permitieron los primeros asentamientos de pequeños poblados, en un poblamiento lineal y disperso característico en las cuencas de los ríos del Pacífico colombiano (Villa 20Ir).

Las juntas de acción comunal pretendían mejorar las condiciones de vida de las localidades mediante la organización de los campesinos. Estas entidades constituyeron una estrategia de organización, mediante la planificación consensuada de actividades colectivas. El destaponamiento de los ríos y la limpieza y adecuación de los caminos eran algunas de las actividades que realizaban, pero también presionaban a los gobiernos municipales u otras entidades con presencia local a propósito de asuntos de interés común, como las escuelas, los servicios de salud y las tiendas comunitarias.

Como lo refiere Leopoldo García, uno de los líderes campesinos del río Truandó involucrado en la gestación de estas juntas de acción comunal en el bajo Atrato:

La idea de las juntas de acción comunal al principio fue idea de la misma gente, porque a uno no hacían sino utilizarlo, uno era un servil del Gobierno, de las administraciones y nunca nos daban nada. Entonces ya vimos nosotros que era mejor uno organizarse porque si íbamos a construir una escuela era importante que nosotros pusiéramos lo que tuviéramos al alcance y así obligábamos al Gobierno, yo ya traía una idea. Entonces comenzamos a organizarnos, a construir escuelas, el puesto de salud, a limpiar los ríos, 
los caminos. (Entrevista a Leopoldo García realizada por Armando Valencia y el autor, Riosucio, enero de 20II)

Con miras a consolidar una estrategia organizativa de mayor alcance, hacia principios de los años ochenta fueron creadas las Asocomunales (Asociaciones de Juntas de Acción Comunal), las cuales reunían diferentes juntas de acción comunal de una misma cuenca o zona. El propósito era aunar esfuerzos para encarar problemáticas compartidas. No obstante, la presencia cada vez más evidente de las dinámicas político-electorales en las juntas de acción comunal y en las Asocomunales fue el detonante de la creación de una nueva estrategia organizativa, que se concretaría en la Organización Campesina del Bajo Atrato (Ocaba). Para mediados de los años ochenta, surgió la idea de crear una organización campesina de carácter regional que, en principio, retomaba como base el trabajo de las juntas de acción comunal y creaba comités locales.

La idea surgió con el apoyo de los misioneros y de algunos líderes locales: "La Ocaba surge de un trabajo paciente y de concientización realizado cuenca por cuenca por los misioneros claretianos y algunos líderes campesinos de la región incentivando la organización comunitaria [...]" (Ramírez s. f., 6). La parroquia de Riosucio fue crucial en el nacimiento y consolidación de Ocaba: “[...] con una idea del padre Javier [Pulgarín], que era el párroco de Riosucio, de que teníamos que conformar una organización de base que respondiera por toda la problemática del bajo Atrato. En esa época se hizo reuniones en todas las comunidades, por cuencas. Por último, se hizo una gran asamblea en Riosucio" (entrevista con Antonio Ospina y Leopoldo García, a cargo de Mauricio Pardo y Manuela Álvarez, Quibdó, octubre de I998).

El esfuerzo de los misioneros por la "organización” de los campesinos, entendido como parte de su labor misional, se explica por las transformaciones ligadas al Concilio Vaticano II y al posicionamiento de la teología de la liberación entre algunos sectores de la Iglesia, desde unos años atrás; y era una actividad que no se limitaba al bajo Atrato (Valencia 20II, I4). Para la misma época, por ejemplo, en el medio Atrato los misioneros (claretianos y del Verbo Divino) realizaban un trabajo organizativo con los campesinos negros, que llevaría a la creación de la Asociación Campesina Integral del Atrato (ACIA). Desde muy temprano, estas dos experiencias organizativas estuvieron comunicadas e intercambiaron visitas y 
puntos de vista, no solo en el plano de los equipos misioneros que las apoyaban, sino también en el de los líderes.

Así, por ejemplo, uno de los líderes fundadores de Ocaba afirmaba: "La idea de crear Ocaba fue en el momento [que] nosotros fuimos a Quibdó y vimos la ACIA, y estuvimos en una reunión que ellos nos invitaron. Entonces de allá sacamos la idea y trajimos documentación y comenzamos a recorrer todos los ríos" (entrevista con Leopoldo García, citada). El viaje a Quibdó fue auspiciado y financiado por la parroquia, para conocer un proceso organizativo campesino en el que los misioneros estaban estrechamente involucrados. No fue el único, ya que "[...] la Iglesia generó intercambios con otras organizaciones para que ellos vieran que era muy importante organizarse [...]" (entrevista con Armando Valencia, sacerdote claretiano de la parroquia de Riosucio, realizada por Josué Sarmiento y Nadia Umaña, Riosucio, 9 de diciembre de 20Io). No obstante, pocos intercambios tuvieron tal impacto como el que se llevó a cabo con la ACIA. El modelo organizativo y discursivo de esta entidad, que estaba apenas gestándose por aquellos años, fue retomado para orientar el trabajo con los campesinos en los ríos y propiciar la creación de Ocaba. Esta visita tuvo un notable efecto en los campesinos del bajo Atrato: "A nosotros lo que nos impactó fue ver a los negros unificados, a los negros organizados. Todos trabajando por unos ideales comunes. Entonces de ahí aprendimos” (entrevista con Leopoldo García, citada).

La Ocaba amerita ser considerada como una respuesta organizativa a una problemática local: la forma como las grandes empresas extraían los recursos madereros, sin mayor participación de los habitantes de los bosques explotados. Dado que el Gobierno central y la instancia ambiental departamental (Codechocó) actuaban con base en el supuesto de que gran parte del bajo Atrato hacía parte de la reserva forestal, entregaban permisos de explotación a los empresarios madereros y con ello desconocían la existencia de los pobladores locales. El malestar de los campesinos, que eran testigos de la entrada de las grandes empresas para extraer la madera de los lugares donde residían, sin que ellos mismos obtuviesen mayores beneficios, se hizo cada vez más palpable. Este malestar fue capturado por las palabras de Leopoldo García:

Imagínese, aquí había seis empresas madereras exportando madera para el exterior, cuando la que menos tenía, tenía seis tractores 
saliendo del monte, por ahí seis remolcadores jalando todo el día, todos los días. Pero el negro no tenía derecho. El Gobierno desde Bogotá les daba sus grandes permisos, le entregaba a una empresa un permiso por diez años, por veinte años y uno apenas viendo. Y lo peor no era eso. Lo peor era que si tenían que extraer una madera que estaba detrás de la finca de uno, entraban sin permiso y extraían su madera destruyendo lo que fuera. (Entrevista con Leopoldo García, citada)

Las disputas sobre estas formas de extracción forestal permiten decantar un discurso por la defensa de los recursos naturales. Esta defensa le otorgó identidad organizativa a Ocaba y articuló su agenda durante sus primeros años. Desde la perspectiva organizativa, la actividad extractiva de las empresas madereras empezó a ser referida cada vez más como expresión de una lógica irracional, cuyas consecuencias eran la destrucción del bosque y el empeoramiento de la pobreza de los campesinos que lo habitaban: "Por largos años las empresas madereras han explotado de una manera irracional e injusta nuestros recursos naturales" (Cabildo Mayor Indígena de la Zona del Bajo Atrato [Camizba] y Organización Campesina del Bajo Atrato [Ocaba] 1992, 4). Así, el entonces secretario de la Ocaba, José Isidro Cuesta, caracterizaba a esta como "[...] una organización de campesinos negros y mestizos organizados para luchar por unos objetivos comunes [...] [que] [n]ació de las dificultades que en el medio se venían presentando, como la explotación irracional de los recursos naturales [...]" (Cuesta 1993, I39).

Para la organización, que actualmente se considera como una heredera y continuadora de las luchas de Ocaba, es claro que en aquel entonces estaba en juego el control de los recursos madereros y de las formas de explotación: "La gran lucha de Ocaba era parar la explotación irracional de los recursos, la organización buscaba que las empresas pidieran permiso y concertaran con las comunidades" (Asociación de Organizaciones y Consejos Comunitarios del Bajo Atrato [Ascoba] 2007, 2). En el mismo sentido, uno de los actuales y más visibles líderes de esta organización enmarca la historia de la Ocaba en este relato de la lucha por la defensa de los recursos naturales: "Los primeros trabajos que realizó la organización Ocaba fueron de concientización de sus miembros de por qué la importancia de la organización como medio para luchar con las empresas por los recursos naturales que estaban explotando [...] sin tener en cuenta a los verdaderos dueños, los campesinos" (Ramírez s. f., 7). 
Como veremos en los siguientes párrafos, estas luchas por los recursos naturales desde una organización campesina se transformaron en los años noventa en luchas étnico-territoriales, en las que los recursos naturales fueron subsumidos en la noción de territorio y el sujeto campesino se etnizó para resaltar al sujeto de derecho constituido por las "comunidades negras". Este es, precisamente, el resultado del proceso de etnización que, en el caso del bajo Atrato, se asocia a dinámicas nacionales como la participación de Ocaba en la movilización en torno a la Asamblea Nacional Constituyente y su presencia en la Comisión Especial para las Comunidades Negras en la reglamentación del artículo transitorio $\mathrm{n} .^{\circ} 55$.

El proceso de etnización derivado del giro al multiculturalismo se hizo evidente en el discurso y en la estrategia organizativa en el bajo Atrato hacia principios de los años noventa. Así, “[d]e una lucha campesina [...] se pasa a una étnico-territorial cobijada por el naciente proceso de etnización de las comunidades negras en el país" (Valencia 20II, 20). Estas transformaciones asociadas al multiculturalismo son explícitamente planteadas por algunos líderes de las organizaciones: “[...] lo étnico surge en los años 9I en plena Constituyente. Ahí surge eso cuando nos dejan un artículo transitorio allí. Entonces ya nosotros que debiéramos luchar por ser reconocidos como grupo étnico" (entrevista con Antonio Ospina y Leopoldo García, citada).

Las movilizaciones en contra de la celebración del quinto centenario del "Descubrimiento" también fueron un escenario de acercamiento a las luchas indígenas de orden nacional, que para entonces ya se habían etnizado. Algunos líderes campesinos negros, recordando lo sucedido en aquellos años, identifican estas movilizaciones como los momentos de emergencia de la idea misma de articular las luchas propias en términos étnicos, como lo hacían ya los indígenas:

Y en esa misma época se viene una gran celebración que se iba a hacer en Bogotá, con la doctora Ana Milena de Gaviria, patrocinada por el Gobierno español de esa época, que decía que debía celebrarse los quinientos años del descubrimiento de las Américas. Entonces nosotros, reconociendo de que en esa época no hubo descubrimiento, ni gloria ni hubo una gran redención, sino que hubo fue genocidio, violación, asesinato, y todo aquello, entonces nosotros conformamos acá un grupo de gente con ese conocimiento claro, esa evidencia, y fuimos a Bogotá. Obstaculizamos esa gran celebración 
que se iba a hacer en el parque Bolívar. [...] Y de ahí nos vino la idea acompañado con los hermanos indígenas de que ellos hablaban de grupo étnico, de autonomía, y todo eso, aprendimos el lenguaje. Entonces ya entramos nosotros también a defender nuestro territorio y a conformar sus grupos étnicos. (Entrevista con Antonio Ospina y Leopoldo García, citada. Énfasis agregado)

De esta manera, se puede argumentar que las coyunturas de la Asamblea Nacional Constituyente y la celebración del quinto centenario constituyeron escenarios de orden nacional e incluso internacional que, asociados a lo que ya sucedía a nivel regional y local (los procesos organizativos de campesinos negros con la ACIA y Ocaba, estrechamente relacionados con la consolidación de los indígenas por medio de la Asociación de Cabildos Indígenas del Chocó [Orewa] y Camizba), propiciaron el desplazamiento de un discurso y de una estrategia organizativa anclados en lo campesino y en la defensa de los recursos naturales, hacia un discurso y una estrategia que se refería a las "comunidades negras" y a sus reclamos de derechos territoriales.

No es extraño que en los estatutos de creación de la Ocaba, en junio de 1989, no se encuentren las palabras (ni mucho menos los conceptos) de territorio, comunidades negras, prácticas tradicionales de producción o identidad, que serán cruciales para una articulación etnicista (cfr. Ruiz 2006, 235-236). Como lo subraya Valencia: "La concepción global que se vislumbra en el documento de los estatutos es la de una organización de campesinos (en ningún lado aparece siquiera la palabra de negro o campesino negro) que buscaba el bienestar de sus socios y el desarrollo económico de sus comunidades" (2OII, 20).

Aunque para principios de los años noventa se hace evidente la consolidación de la etnización de las "comunidades negras" en el bajo Atrato, ello no significa que la apropiación e interpretación de los discursos y estrategias de la etnización se generalizaran entre sus pobladores. Entre los pobladores locales, quienes han operado con base en los imaginarios políticos de las comunidades negras como un grupo étnico han sido principalmente algunos activistas de las organizaciones y consejos comunitarios. Incluso entre estos, es fácil hallar interesantes inflexiones de lo que define a un grupo étnico, de qué es la cultura o de quiénes hacen parte de las comunidades negras. 


\title{
TENSIONES Y PROBLEMÁticAs EMERGENTES
}

El ste desplazamiento de lo simplemente campesino hacia la condición étnico-territorial de las comunidades negras encontró un gran escollo en el hecho de que las dinámicas poblacionales del bajo Atrato han sido muy diferentes de las de otras zonas del Pacífico colombiano donde la población negra es la gran mayoría. En el bajo Atrato, sobre todo en su margen oriental, hay una significativa presencia de chilapos, y en menor proporción, de paisas. En la margen occidental del Atrato, donde en términos generales hay una presencia predominante de gente negra, se encuentran desde hace varias décadas asentamientos exclusivamente de chilapos, aunque también chilapos y paisas han formado parte de asentamientos mayoritariamente negros. Aunque los paisas no parecen haber tenido mayor papel en la gestación y consolidación de la Ocaba, los chilapos sí lo hicieron. Es más, el presidente de Ocaba fue cambiado en la época de las discusiones del artículo transitorio 55 porque era chilapo:

\begin{abstract}
Después de la muerte de Cali, se nombró a Ángel del Toro como presidente. Trabajó dos años y le cayó una enfermedad y murió. Entonces se hizo nueva asamblea y allí se eligió un señor Gerardo Vidar [...]. Llegó un momento que como él era chilapo, o cordobés, entonces ya estábamos discutiendo el artículo transitorio 55 y las comunidades negras no lo permitían. Fue el debate aquí en la consultiva, se llevó a Bogotá y ya todas las organizaciones de los cuatro departamentos más sentidos de comunidades negras pusieron tropiezo. Entonces hubo necesidad de hacer nueva elección. Podía ocupar cualquier otra posición en la organización, mas no ser el representante legal de organización de comunidades negras. Entonces ya hubo otra elección y allí se nombró al señor Jacob Orejuela Mosquera ${ }^{15}$. (Entrevista con Antonio Ospina y Leopoldo García, citada)
\end{abstract}

I5 La carta de renuncia de Gerardo Vidar Ramos, firmada el 23 de noviembre de I99I, se dirige a la Asamblea general de la Ocaba realizada ese mismo mes (archivo de la parroquia de Riosucio).

I6 El saneamiento de los resguardos se refiere a la compra, por parte de la entidad estatal, de las fincas de los propietarios no indígenas que
Desde la perspectiva de los líderes y miembros negros de las ahora organizaciones étnico-territoriales, la presencia chilapa en el bajo Atrato implicó dos posiciones. De un lado, estaban quienes consideraban que los chilapos no tenían derecho al territorio colectivo de las comunidades negras derivado de la Ley 70, y lo por tanto había que pensar en una modalidad parecida a la del saneamiento de resguardos ${ }^{16}$, para 
que fueran reubicados en otros lugares o para que se pudieran quedar con sus propiedades familiares ya establecidas, pero sin disfrutar del derecho al territorio colectivo, y con participación en la organización pero sin posibilidad de ocupar puestos directivos están dentro del terreno declarado como resguardo, o al desalojo por la fuerza de los poseedores de mala fe.

I6 Es relevante notar en esta cita el vocabulario de los últimos años: ya empiezan a circular, en lugar de negros o comunidades negras, la palabra afrodescendiente; y, en vez de chilapo, la palabra mestizo. y de representación legal. Esta posición, que era minoritaria, terminó cediendo, y hoy no tiene mayor asidero en los discursos de los líderes. La segunda posición, que terminó por ser adoptada, argumentaba que los chilapos debían ser considerados como ocupantes de buena fe, pues muchos de ellos habían llegado al bajo Atrato hacía varias décadas y, en el estrecho contacto con las comunidades negras, se habían apropiado de una buena parte de sus prácticas tradicionales de manejo del entorno, e incluso habían establecido lazos de parentesco con miembros de estas (Ruiz 2006: 234). Así, en un documento relativamente reciente, se menciona esta disputa en los siguientes términos:

Se dio una importante discusión, llegando a la conclusión que a lo largo de más de 30 años se habían establecido fuertes relaciones de parentesco, compadrazgo y amistad entre la población afro y mestiza que nos hacía parte de la cultura bajoatrateña. Esto llevó a que las comunidades afrodescendientes adoptaran a los mestizos [chilapos] en su territorio como ocupantes de buena fe mediante un acuerdo de amparo, y los mestizos a su vez, se acogen a la Ley 70 desde sus principios de protección a la identidad cultural y conservación de los ecosistemas a través de las prácticas tradicionales de producción ${ }^{16}$. (Ascoba 2007, I)

Ahora bien, este no es un asunto tan saldado como parece. Según William Villa:

En las cuencas en donde las comunidades de chilapos son demográficamente significativas, a pesar de los acuerdos realizados hacia el pasado entre chilapos y afros para la titulación, persiste la tensión que se expresa en el interrogante sobre los derechos de los chilapos en el orden de lo territorial o respecto a su papel en el gobierno local o en la representación de las cuencas. $(2009,7)$

Todavía sin haberse sancionado la Ley 70 de 1993, que establecía la posibilidad de la titulación colectiva para las comunidades negras de la región del Pacífico, hacia finales de I992, en 
el marco del IV Encuentro Interétnico del Bajo Atrato se planteó explícitamente la problemática del territorio en relación con los campesinos mestizos. Vale la pena citar en extenso el documento de conclusiones de este encuentro, que fue firmado por la organización indígena (Camizba) y por la campesina (Ocaba):

Desde hace unos treinta años aproximadamente indígenas y negros hemos visto llegar a nuestro territorio campesinos mestizos de Antioquia, Córdoba, Valle y otras regiones. Las razones que ellos señalan son, entre otras, la explotación de sus tierras por terratenientes, violencia, persecución política y falta de tierras.

Muchos campesinos han aprendido y asumido en sus prácticas de cultivo y manejo de los recursos una utilización racional de acuerdo a las características de este bosque húmedo tropical.

Hay otros campesinos que no le han dado a este un manejo adecuado, prueba de ello son las costumbres y prácticas que vienen utilizando, tales como quemas para cultivos y recolección de tortugas, establecimiento de monocultivos, tala indiscriminada del bosque, etc., desconociendo que la constitución de este bosque húmedo tropical es sumamente frágil, que no permite que sus tierras sean utilizadas igual que en otras regiones del país.

Finalmente, encontramos campesinos y terratenientes que han llegado con el único fin de explotar y saquear los recursos naturales y apropiarse de la tierra.

Por tanto, consideramos importante iniciar, a partir de este Encuentro, un proceso de reflexión y diálogo con los campesinos mestizos, que como dijimos anteriormente se han adaptado a este territorio, con el fin de definir criterios en torno a la titulación colectiva de su territorio, administración y manejo de los recursos naturales, prácticas tradicionales de producción, llegada de otros campesinos, etc.

Otro diálogo tendremos que adelantar las organizaciones con los campesinos que todavía tienen un concepto capitalista de la tierra y de los recursos naturales (solo les interesa para el negocio), porque van en contra de la propuesta de titulación colectiva y familiar, y de la autonomía en el manejo, explotación y control de estos recursos. (Camizba y Ocaba I992, I2-I3)

Cabe subrayar cómo desde la perspectiva del Encuentro Interétnico (esto es, de negros, indígenas y mestizos), en cuyos discursos evidentemente ya estaba operando el proceso de etnización de las comunidades negras, se estaban estableciendo 
distinciones entre diferentes tipos de mestizos, no solo por su lugar de origen (Antioquia, Córdoba y Valle), sino, fundamentalmente, por su lógica económica y ambiental. Según esta lógica, había unos mestizos que ejercían prácticas adecuadas al entorno, prácticas racionales, tradicionales y en correspondencia con la propuesta de la titulación colectiva y familiar; pero también se encontraban otros cuyas prácticas contrastaban con las de los primeros, en tanto no eran adecuadas al entorno, ya que eran irracionales, capitalistas y operaban en el marco de la explotación y la propiedad privada.

Pero, por su parte, los campesinos mestizos tenían sus propias ideas acerca de la Ley 70, y en concreto sobre los primeros borradores de lo que sería el artículo I745, que desarrolla el capítulo III, sobre titulación colectiva; ellos percibieron esta ley como una amenaza a sus derechos. Como lo anota Enrique Ramírez en un documento escrito a principios de la primera década del siglo xxi:

Inicialmente la poca divulgación y la mala interpretación de la reglamentación de la Ley 70 trajo como consecuencias enfrentamientos entre las diferentes etnias que estaban habitando el bajo Atrato (negros, indígenas, cordobeses, antioqueños, etc.). Los primeros borradores del capítulo $3 .^{\circ}$ de la Ley 70 que fueron trabajados en su mayoría por organizaciones del medio y alto Atrato y otras partes del país, trajeron una ola de enfrentamientos entre la población del bajo Atrato pues desconocían la mezcla de etnias que habitaban el bajo Atrato. Muchos mencionaban que la ley era única y exclusiva para los negros. Y que aquellos que no fueran negros tenían que salir del territorio. (Ramírez s. f., II)

Es evidente que, en el bajo Atrato, el multiculturalismo expresado en el proceso que condujo a la Ley 70 propició una serie de tensiones en las expresiones y dinámicas organizativas, que no existían antes de la etnización. Las disputas entre negros y chilapos a propósito de la Ley 70 no eran siquiera pensables en el marco de organizaciones que hacían referencia a la noción de campesino en general, sin distinciones de orden étnico o I7 Acamuri nació en el marco del conflicto con las empresas madereras, en los años ochenta, como una disidencia de Ocaba, pero desde su mismo nombre y en su estrategia organizativa, igual que Ocaba, hacía referencia al campesino como el sujeto político constitutivo (Ruiz 2006, 236). racial, como Ocaba o Acamuri (Asociación Campesina del Municipio de Riosucio) ${ }^{17}$. En este sentido, el particular proceso de etnización que tiene lugar en 
el bajo Atrato, derivado del giro al multiculturalismo, constituye a un inusitado sujeto (las comunidades negras) que fractura los términos en los que venía consolidándose el imaginario político local en torno al campesino, e inserta un conflicto que antes no existía en el plano organizativo ${ }^{18}$.

Los efectos de este giro al multiculturalismo no se circunscriben a esta fractura y a este conflicto. En un registro aún más sutil, lo que se cataliza es el desplazamiento hacia la interpretación racial y culturalista de las prácticas y luchas políticas locales. En las citas transcritas unos párrafos atrás, es evidente cómo mestizo

I8 Con esto no quiero afirmar que las tensiones entre chilapos y negros se derivan exclusivamente del proceso de etnización y de la Ley 70, como si antes no hubiese conflictos entre ellos. Solo quiero subrayar que los términos en los cuales se articulan y acentúan las tensiones con el proceso de etnización y la Ley 70 son diferentes, pues ambas poblaciones se posicionan asimétricamente y resulta obliterado un sujeto político, el campesino, que era el eje del proceso organizativo. I9 Sobre la caracterización teórica y crítica del culturalismo, así como de sus políticas de la identidad, véase Grimson (2OII). es una categoría que empieza a circular con fuerza. Hoy es fácil encontrar, en boca de los líderes de las organizaciones, en sus documentos y narrativas, este término (la más de las veces como eufemismo de chilapo). Como lo plantea Daniel Ruiz: "Con el advenimiento de la Ley 70 y la posibilidad de gozar del derecho de titulación colectiva, las identificaciones respaldadas en lo étnico, lo racial o el color llegaron a ser equiparables y prácticamente intercambiables” (2006, 2I4). Para los años 2003 y 2004, el mismo autor indicaba que "[...] durante los talleres que se hicieron en los diferentes Consejos Comunitarios se hizo recurrente el uso de conceptos como raza, cultura y etnia, para identificar las diferencias entre negros y chilapos [...]" (2006: 2I7).

Además de este principio de inteligibilidad racializante, el culturalismo, con sus fuertes tendencias idealizantes, se posiciona localmente en el plano organizativo ${ }^{19}$. Como se enuncia claramente en la cita transcrita de Camizba y Ocaba (I992, I2I3), las comunidades indígenas y negras son imaginadas como nativos ecológicos que responden a una lógica de armonía con la naturaleza. En otro pasaje del documento, en referencia específica a las comunidades negras, esta noción de armonía, contrapuesta a la de mercantilización, es la que ilustra la idea de territorio:

Es importante decir que para nosotros, las comunidades negras, el territorio no es un objeto comercial sino un espacio donde se da la 
vida por excelencia, proporcionando los recursos naturales necesarios para garantizar la reproducción de nuestra vida. Para nosotros, el territorio abarca el conjunto de los recursos naturales renovables y no renovables, las aguas, el aire, los animales, las flores, los minerales y las fuerzas sobrenaturales que rigen el conjunto de la naturaleza y viven en su interior. (Camizba y Ocaba I992, Io)

Aunque sin lugar a dudas con unos efectos políticos que pueden posicionar en ciertas situaciones a las organizaciones, lo problemático de este tipo de lecturas es que obturan una compresión más adecuada y densa de la situación de las poblaciones locales. Esto es particularmente evidente en el caso de la explotación maderera, ya que al presentar a las comunidades como nativos ecológicos, en idílica armonía con la naturaleza, no se da mucha cabida a la comprensión de las intrincadas dinámicas y relaciones de las poblaciones locales con la extracción de madera en el bajo Atrato (Villa 20II). Más complicado aún es cuando, en nombre de estas interpretaciones, se introducen conflictos incluso en el seno de las mismas poblaciones negras (o indígenas), con respecto a quienes parecen no comportarse como debieran hacerlo. De esta forma, en el bajo Atrato el multiculturalismo y la etnización no solo han operado como una representación idealizada de las comunidades negras, sino que han insertado de forma prescriptiva un inusitado sujeto moral, que define cómo se debería ser, en franca distancia con lo que suele suceder. El análisis de Daniel Ruiz (2006) señala cómo ello tiene unos efectos performativos: mostrarse encarnando una racionalidad ecológica sostenible, incluso los chilapos, que habían sido representados, en el ámbito local, como el paradigma de las prácticas ambientales censurables.

Al configurar determinado sujeto político (las comunidades negras como un grupo étnico), el plano organizativo étnico-territorial adquiere una visibilidad tal, que al momento del retorno al bajo Atrato de las poblaciones desplazadas se constituyó, en 2003, una nueva organización que sentó sus bases en lo étnico-territorial: la Asociación de Consejos Comunitarios y Organizaciones del Bajo Atrato (Ascoba) ${ }^{20}$. Esta organización ejecuta una serie de labores e interlocuciones en

20 En 1996 los paramilitares se tomaron el casco urbano de Riosucio, y con el apoyo de las Fuerzas Armadas y de policía, en nombre de la guerra contrainsurgente desataron en la zona rural del bajo Atrato el mayor desplazamiento poblacional dado en el país. Los líderes de Ocaba y Acamuri fueron listados como guerrilleros por los paramilitares, y fueron 
asesinados muchos de ellos, por lo que estas organizaciones desaparecieron. Para un estudio de las dinámicas del conflicto y las respuestas organizativas en el bajo Atrato, ver Mera (2006) y Valencia (2OII). las cuales es fácil encontrarse con palabras como territorio, cultura, identidad, etnoeducación, etnosalud y etnodesarrollo, terminología que es un indicador de cómo los líderes de la organización, así como algunos de los miembros más cercanos, que hacen parte de los consejos comunitarios, se han apropiado del multiculturalismo. No solamente el Estado los interpela a menudo con estos términos (aunque no solo con estos), sino también las entidades no gubernamentales nacionales y extranjeras que tienen una fuerte presencia en la zona desde finales de los noventa, dedicadas a labores humanitarias y de atención a población desplazada y de retorno.

Ahora bien, si uno se queda en lo que muchos de los activistas enuncian y en lo que escriben en sus documentos, pareciera que el proceso de etnización ha tenido un gran calado y que el multiculturalismo se encuentra localmente articulado. No obstante, como lo evidencia William Villa (2009), el uso de esta terminología por parte de la organización y de sus activistas no necesariamente se corresponde con las conceptualizaciones o prácticas esperadas. De ahí que, por ejemplo, “[...] el etnodesarrollo por el que propugna es simple enunciado sin contenido" (Villa 2009, Io), o que a pesar del reiterativo uso del término territorio:

[...] no existen iniciativas en las que claramente se pueda identificar una propuesta de manejo territorial en la que sea perceptible una visión respecto a la política ambiental, lo productivo, la propiedad o usufructo de la tierra, el papel del gobierno local, los conflictos interétnicos y en general la decantación del significado del manejo colectivo del territorio. (Villa 2009, 9)

Esto ha estado aparejado con el hecho de que los consejos comunitarios y la organización regional, en tanto interlocutores legítimos del Estado, de entidades del país o extranjeras y de los empresarios con intereses allí, se encuentren ante múltiples y contradictorias demandas, con efectos que podrían considerarse empoderantes, pero también (y a veces por eso mismo) generadores de dependencias que terminan por configurar sus agendas, cuando no alimentando ciertas burocracias étnicas. La etnografía de estas demandas y de sus efectos es una labor que amerita, al menos, otro artículo. Por ahora, baste indicar brevemente que las expresiones organizativas regionales y locales que apelan a 
lo étnico-territorial en el bajo Atrato operan, en gran parte, con una lógica de formulación y ejecución de diversos proyectos con financiación del Gobierno o de entidades extranjeras. Así, se han venido subsumiendo en una dinámica de "oenegización" en su propia concepción y práctica, y ha resultado socavada la dimensión de la lucha política, por la cual se constituyeron la movilización campesina en los años ochenta y el primer momento de la etnización a comienzos de los noventa.

\section{Conclusiones}

-n un documento escrito por el actual presidente de la organización étnico-territorial regional del bajo Atrato, Ascoba, se hace Lla siguiente reflexión, a propósito de los momentos iniciales de la organización campesina:

[...] en ese entonces no hablábamos de etnicidad o del reconocimiento a los derechos asociados con la cultura o la raza, pues solo hasta una época muy reciente Colombia reconoció jurídica y efectivamente la existencia de grupos humanos con cultura, conocimientos, tradiciones, saberes y prácticas propias como la de los indígenas, negros, raizales y algunos grupos mestizos. (Ramírez s. f., 3)

De acuerdo con lo planteado por Ramírez, en este artículo examinamos cómo el proceso de etnización en el bajo Atrato se configura a comienzos de los años noventa, asociado a factores de orden nacional (como el artículo transitorio 55 de la Constitución Política de 1991 y la Ley 70 que lo reglamenta), internacional (como el giro al multiculturalismo en la región o la campaña de rechazo a la celebración del quinto centenario del "Descubrimiento"), regional y local (las transformaciones en las concepciones y prácticas de los misioneros, la consolidación de las organizaciones indígenas, la emergencia de organizaciones campesinas negras en el medio y bajo Atrato).

Lo que denominamos el multiculturalismo etnicista, tanto si lo consideramos en un sentido restringido (como política de Estado) o mucho más amplio (como gubernamentalidad), se encuentra estrechamente relacionado con esta etnización. En el bajo Atrato, la etnización es su efecto más visible. Por lo tanto, no pocos discursos y estrategias organizativas empiezan a gravitar en 
torno a un inusitado sujeto de derechos (las comunidades negras), a perfilar otros principios de inteligibilidad (como la cultura, lo tradicional, el territorio) y a redefinir nuevas subjetividades (identidad étnica). Ahora bien, como ya lo indicamos, esto no significa que la etnización sea un proceso que involucre de la misma manera a los pobladores locales. Para muchos, todavía hoy, es un discurso en gran parte ajeno e incluso desconocido. Son los activistas de los consejos comunitarios y de las organizaciones quienes han sido más interpelados, aunque con obvias diferencias e inflexiones.

Las tensiones y problemáticas asociadas al multiculturalismo en el bajo Atrato estudiadas en el artículo fueron: I) la fragmentación de un proceso organizativo cuyo sujeto era el campesino; 2) la asimetría que posiciona a las comunidades negras, al tiempo que subsume (cuando no margina) a los que ahora aparecen como mestizos (chilapos); 3) el culturalismo como impase epistémico para la comprensión de las dinámicas locales y regionales, en tanto supone un reduccionismo cultural y una idealización de los sujetos étnicos; y 4) una paulatina socavación de la confrontación y de la lucha políticas, debido a la institucionalización y sedimentación de la organización y de los consejos comunitarios, que van de la mano con una naciente burocracia étnica y una "oenegeización” de la concepción y la práctica organizativas.

De manera general, con base en lo presentado en el bajo Atrato, se puede plantear que uno de los grandes problemas que trae aparejados el multiculturalismo etnicista consiste en que la diferencia corre el riesgo de inscribirse en un reduccionismo cultural (y a veces producir una imagen folclorizante) o en uno etnicista (en el cual el otro étnico de la nación es encarnado por unas figuras de indianidad o negridad hiperreales). Otro de los grandes problemas es que puede operar (aunque no necesariamente) como una máquina antipolítica ${ }^{21}$, en tanto que la lógica de la burocracia étnica y la del proyecto logran hasta cierto punto canalizar y reemplazar malestares sociales

2I Esta categoría ha sido sugerida por James Ferguson (I994) en su conocido análisis del desarrollo en Losotho. Considero que ofrece un gran potencial analítico para explorar etnográficamente los efectos despolitizantes del multiculturalismo. que alimentaban imaginarios $\mathrm{y}$ luchas políticas.

Ahora bien, estos problemas no son exclusivos del multiculturalismo etnicista, también son 
propios de las otras modalidades del multiculturalismo, ya que la apelación al diferencialismo culturalista suele suponer el desplazamiento de otros énfasis y tipos de articulación de las luchas políticas que no sean en nombre de la diversidad. Esto no quiere decir que considere que no vale la pena defender la valoración ni el posicionamiento de la diferencia que se pueden atribuir al multiculturalismo, ni que le desconozca a este una serie de contribuciones históricas a la imaginación política y teórica. Lo que quiero argumentar es que el reduccionismo culturalista y su política de la identidad pueden llegar a tener un efecto perverso, paralizante, análogo al reduccionismo de clase y de sus sujetos, propio de la revolución predominante hace algunas décadas.

\section{ReFERENCiAs}

Agudelo, Carlos Efrén. 2005. Retos del multiculturalismo en Colombia. Bogotá: Instituto Colombiano de Antropología e Historia y La Carreta.

Asociación de Organizaciones y Consejos Comunitarios del Bajo Atrato (Ascoba). 2007. "El bajo Atrato, Io años de desplazamiento forzado". Ponencia presentada en la conmemoración de los diez años del desplazamiento forzado, Riosucio, Chocó.

BRIONES, Claudia. 2002. "Mestizaje y blanqueamiento como coordenadas de la aboriginalidad y nación en Argentina". Runa 23: 6I-88.

Cabildo Mayor Indígena de la Zona del Bajo Atrato (Camizba) y Organización Campesina del Bajo Atrato (Осaba). ig92. Boletín del Cuarto Encuentro Interétnico del Bajo Atrato.

Castillo, Luis Carlos. 2007. Etnicidad y nación: el desafío de la diversidad en Colombia. Cali: Universidad del Valle.

Colombia, Contraloría General de la Nación. 1943. Geografía económica del Chocó. Bogotá: Imprenta Nacional.

CuESTA, José IsIDRo. 1993. “Organización campesina del bajo Atrato”. En Contribución africana a la cultura de las Américas, editado por Astrid Ulloa, I37-I43. Bogotá: Instituto Colombiano de Antropología y Biopacífico.

Dagnino, Evelina. 2004. "Confluencia perversa, deslocamientos de sentido, cirse discursiva”. En La cultura en las crisis latinoamericanas, editado por Alejandro Grimson, 195-216. Buenos Aires: Clacso.

Ferguson, James. 1994. The Anti-Politics Machine. "Development," Depoliticization, and Bureaucratic Power in Lesotho. Minneapolis: University of Minessota Press. 
Foucault, MichEL. I978/1999. “La 'gubernamentalidad' ”. En Obras esenciales, vol. III, Estética, ética y hermenéutica, I75-197. Barcelona: Paidós.

GrandA, GERMÁn DE. I977. Estudios sobre un área dialectal hispanoamericana de la población negra: las tierras bajas occidentales de Colombia. Bogotá: Instituto Caro y Cuervo.

Grimson, Alejandro. 20ir. Los límites de la cultura. Crítica de las teorías de la etnicidad. Buenos Aires: Siglo XXI.

Gros, Christian. I999. Políticas de la etnicidad. Identidad, Estado y modernidad. Bogotá: Instituto Colombiano de Antropología e Historia.

Hale, Charles. 2002. "Does Multiculturalism Menace? Governance, Cultural Rights and the Politics of Identity in Guatemala”. Journal of Latin American Studies 34: 485-524.

Hall, Stuart. 2000/20IO. "La cuestión multicultural”. En Stuart Hall. Sin garantías: trayectorias y problemáticas en estudios culturales, editado por Eduardo Retrepo, Catherine Walsh y Víctor Vich, 583-618. Bogotá, Popayán, Lima y Quito: Instituto Pensar, Envión Editores, Instituto de Estudios Peruanos y Universidad Andina Simón Bolívar.

INDA, JONATHAN XAVIER. 2005. "Analytics of the Modern: An Introduction”. En Anthropologies of Modernity: Foucault, Governmentality, and Life Politics, editado por Jonathan Xavier Inda, I-20. Malden: Blackwell.

LÓPEZ DE MESA, LuIs. I92Oa. “Segunda conferencia”. En Los problemas de la raza en Colombia, editado por Luis López de Mesa, 79-IIo. Bogotá: Imprenta Linotipos.

LÓPEZ DE MESA, LuIs. I92ob. “Tercera conferencia”. En Los problemas de la raza en Colombia, editado por Luis López de Mesa, III-I49. Bogotá: Imprenta Linotipos.

LóPEZ DE Mesa, Luis. I934. Cómo se ha formado la nación colombiana. Bogotá: Bedout.

MERA, GABriEL. 2006. “Guerra, desterritorialización, resistencia y resignificación en las comunidades afrodescendientes del Cacarica, Jiguamiandó y Curvaradó, bajo Atrato chocoano”. Trabajo de grado, Universidad del Cauca, Popayán.

MEZA, CARLOS ANDRÉs. 2006. "Territorios de frontera: embate y resistencia en la cuenca del río Cacarica”. Universitas Humanística 62: 385-429.

Mosquera, Claudia y Ruby LEÓN. 2009. "Acciones afirmativas en Colombia: entre paradojas y superposiciones de lógicas políticas y académicas". En Acciones afirmativas y ciudadanía diferenciada étnico-racial negra, afrocolombiana, palenquera y raizal. Entre bicentenarios de las Independencias y Constitucion de I99I, editado por Claudia Mosquera y Ruby León, I-XXXVI. Bogotá: Investigaciones CES y Universidad Nacional de Colombia. 
Osorio, Jairo. 2006. Pueblos itinerantes de Urabá. La historia de las exclusiones. Retrato. Universidad Internacional de Andalucía, sede Iberoamericana Santa María de la Rábida, http://dspace.unia.es/ bitstream/IO334/63/1/0004_Osorio.pdf

Pardo, Mauricio, ed. 200I. Acción colectiva, Estado y etnicidad en el Pacífico colombiano. Bogotá: Instituto Colombiano de Antropología e Historia y Colciencias.

PARdO, MAURICIO. 2002. "Entre la autonomía y la institucionalización: dilemas del movimiento negro colombiano". The Journal of Latin American Anthropology 7 (2): 60-85.

Parsons, James. 1997. La colonización antioqueña en el occidente de Colombia. Bogotá: El Áncora.

RAmírez, ERNeSTO. s. f. "Los negros en el continente americano y sus organizaciones”. Inédito.

Ramos, Alcida Rita. I998. Indigenism. Ethnic Politics in Brazil. Madison: University of Wisconsin Press.

Ruiz SERNA, DANIEL. 2006. "Nuevas formas de ser negro. Consideraciones sobre las identidades entre la gente chilapa y negra del bajo Atrato chocoano". En Identidades culturales y formación del Estado en Colombia, editado por Íngrid Bolívar, 2II-248. Bogotá: Universidad de los Andes.

Rojas, AxEL, ed. 2004. Estudios afrocolombianos. Aportes para un estado del arte. Popayán: Universidad del Cauca.

SEgato, Rita Laura. 2007. La nación y sus otros. Raza, etnicidad y diversidad religiosa en tiempos de políticas de la identidad. Buenos Aires: Prometeo.

UlloA, Astrid. 2004. La construcción del nativo ecológico. Complejidades, paradojas y dilemas de la relación entre los movimientos indígenas y el ambientalismo en Colombia. Bogotá: Instituto Colombiano de Antropología e Historia.

URIBE, MARÍA TERESA. I992. Urabá: ¿región o territorio? Medellín: Corpourabá e Instituto de Estudios Regionales, Universidad de Antioquia.

VALENCIA, ARMANDO. 2OII. “Territorios en disputa: procesos organizativos y conflicto armado en el bajo Atrato”. Trabajo de grado, Universidad de los Andes, Bogotá.

VArgas, Patricia. I999. “Organización social, identidad y territorio de las gentes negras en el río Atrato durante el siglo xvir y sus huellas en la actualidad”. En Construcción territorial en el Chocó, editado por Patricia Vargas, vol. I, 27-66. Bogotá: Instituto Colombiano de Antropología y Plan Nacional de Rehabilitación. 
VILLA, WiLliam. 2009. "Diagnóstico y formulación de plan para el fortalecimiento de las organizaciones Ascoba y Camizba". Informe parcial, Oxfam.

Villa, William. 20Ir. Colonización y conflicto territorial en el bajo Atrato. El poblamiento de las cuencas de la margen oriental. (Versión preliminar). Quibdó: Fundación Universitaria Claretiana y Oxfam.

Wade, Peter. I996. "Identidad y etnicidad". En Pacífico. ¿Desarrollo o diversidad? Estado, capital y movimientos sociales en el Pacífico colombiano, editado por Arturo Escobar y Álvaro Pedrosa, 283-297. Bogotá: Cerec.

WAdE, PETER. 1997. Gente negra, nación mestiza. Dinámicas de las identidades raciales en Colombia. Bogotá: Universidad de los Andes.

Zapata Olivella, Manuel. 1974. El hombre colombiano. Bogotá: Antares. 